\title{
The Development of Children's Information Gathering: To Look or to Ask?
}

\author{
Stanka A. Fitneva, Nietzsche H. L. Lam, and Kristen A. Dunfield \\ Queen's University
}

\begin{abstract}
The testimony of others and direct experience play a major role in the development of children's knowledge. Children actively use questions to seek others' testimony and explore the environment. It is unclear though whether children distinguish when it is better to ask from when it is better to try to find an answer by oneself. In 2 experiments, we examined the ability of 4- and 6-year-olds to select between looking and asking to determine visible and invisible properties of entities (e.g., hair color vs. knowledge of French). All children chose to look more often for visible than invisible properties. However, only 6-year-olds chose above chance to look for visible properties and to ask for invisible properties. Four-year-olds showed a preference for looking in one experiment and asking in the other. The results suggest substantial development in the efficacy of children's learning in early childhood.
\end{abstract}

Keywords: information gathering, questions, testimony, direct experience, confidence

Children's discovery of knowledge through deliberate action is an important aspect of development. Since infancy, children manipulate objects to discover what they do and when their language skills advance, they also begin to ask questions often relentlessly pursuing the satisfaction of their curiosity. By actively and deliberately searching for information children are able to access knowledge at a moment of cognitive readiness; they are not at the mercy of happenstance or adults' ability to identify their interests and needs (Baldwin \& Moses, 1996). Yet the extent to which children's deliberate actions contribute to their knowledge development depends on children's ability to efficiently pursue their informational goals. The allocation of scarce attentional resources to obtain useful information is a key problem for the child in an information-rich environment (Pirolli \& Card, 1999; Simon, 1971). The question we address in this article is how well children choose the appropriate means to obtain information. In particular, can they appropriately choose between looking for themselves and asking others, and how does this ability change with age?

Direct experience and others' testimony have often been investigated in isolation of each other as sources of children's knowledge. Following Piaget, for much of the 20th century, cognitive

This article was published Online First January 14, 2013.

Stanka A. Fitneva, Nietzsche H. L. Lam, and Kristen A. Dunfield, Department of Psychology, Queen's University, Kingston, Ontario, Canada.

Nietzsche H. L. Lam is now at the Max Planck Institute for Psycholinguistics, Nijmegen, the Netherlands. Kristen A. Dunfield is now at the Department of Psychology, Ohio State University.

We thank Dorcas Lam and Antonia Dangalcheva for help with data collection and the families who participated in this research for generously sharing their time. The research was partially supported by a grant from Queen's University.

Correspondence concerning this article should be addressed to Stanka A. Fitneva, Department of Psychology, Queen's University, Kingston, Ontario K7L 3N6, Canada. E-mail: fitneva@queensu.ca development research focused on the importance of children's physical actions and reasoning for the development of knowledge. Recent research shows that children approach social information gathering with earnestness and rigor similar to the ones they display in the search for knowledge through their own activity (Gelman, 2009; Harris \& Koenig, 2006). Although sensitivity to cues about informant reliability develops with age (Einav \& Robinson, 2010; Fitneva \& Dunfield, 2010; Nurmsoo \& Robinson, 2009b), 4-year-old children already demonstrate vigilance toward informants based on characteristics such as informational access, past accuracy, age, and benevolence (e.g., Birch, Vauthier, \& Bloom, 2008; Fitneva, 2010; Jaswal \& Neely, 2006; Koenig \& Harris, 2005; Mascaro \& Sperber, 2009; Sperber et al., 2010). Information gathering, however, is a goal-oriented behavior in which children also often face the problem of selecting among knowledge sources such as their own experience and others' testimony.

One point where children confront the problem of selecting between direct experience and testimony is in integrating and balancing information from these sources. Naturalistic observations provide clear examples that by age four children actively reconcile their personal experience with others' testimony (e.g., Callanan \& Oakes, 1992; Chouinard, 2007; Frazier, Gelman, \& Wellman, 2009; Harris \& Koenig, 2006; Tizard \& Hughes, 1984). Tizard and Hughes's (1984) conversation corpus, for instance, showed how children quiz adults about Santa Claus driven by the conflict between their understanding of how the world works (e.g., fireplaces are hot) and the Santa Claus lore (Santa comes down the chimney).

Experimental research provides further evidence about children's skills at integrating experientially and socially derived information. For example, 4-year-olds are sensitive to cues marking circumstances where learning from others is more effective than direct experience. In particular, 4-year-olds respond to the expression of pedagogical intention with greater receptiveness to the information provided by the informant and by limiting explor- 
atory actions and reliance on their own judgment (e.g., Bonawitz et al., 2011; Buchsbaum, Gopnik, Griffiths, \& Shafto, 2011; Burtler \& Markman, 2012; Jaswal, 2004). They may accept cat as the label of a dog-looking animal when the speaker's intention to teach a label is clear, e.g., "You're not going to believe this, but that is actually a cat!" but not when this intention is not explicit, e.g., "Look at this cat!" (Jaswal, 2004). A number of studies also show that in (nonpedagogical) situations where children's own knowledge contrasts the information they receive from others, they consider the appropriateness of their own and the informant's informational access in deciding whether to retain their beliefs. For example, if an object could be identified by its color and children examined it visually, whereas the informant touched it without looking at it, children retained their own belief about the identity of the object; when the actions were switched, they abandoned their beliefs in favor of the informant's suggestion (Nurmsoo \& Robinson, 2009a; Robinson, Champion, \& Mitchell, 1999; Robinson \& Whitcombe, 2003).

Although children appear to skillfully integrate information from testimony and direct experience (e.g., Robinson et al., 1999), this is not always the case. Two recent studies show that toddlers trust testimony, rather than their own eyes, when the informant has been repeatedly erroneous or has contradicted entrenched perceptual biases such as that dropped objects fall straight down (Jaswal, 2010; Jaswal, Carrington Croft, Setia, \& Cole, 2010). Even though 4-year-olds quickly adjust their trust in these specific tests based on the informant's accuracy (V. Jaswal, personal communication, January 15, 2012), other paradigms show "credulity bias" at this and older ages. Indeed, the vast literature on children's suggestibility addresses the phenomenon of children changing their experientially based beliefs after hearing a contradictory suggestion (e.g., Ceci \& Bruck, 1993, 2006; Melnyk, Crossman, \& Scullin, 2007; Poole \& Lindsay, 2001). Examples of the opposite-children persistently holding to experientially based beliefs in the face of contradicting testimony-are also available. Until about age seven, children ignore instruction on conservation problems and assert that physical manipulations that lead to changes in the visual appearance of a substance (e.g., a stick of play dough is stretched) also lead to changes in its mass (e.g., Field, 1987).

The research reviewed so far typically positions children down the stream of information gathering, at a point where they already have formed some belief. The present research focuses on another point of the information gathering process, namely, the point of deciding what route of information gathering to take: Do children distinguish when it is better to ask from when it is better to find an answer on one's own?

Children's ability to select an action in pursuit of an informational goal has been examined in several studies focusing on children's understanding of the types of knowledge the senses give rise to. By age four, children are able to answer simple yes/no questions, e.g., "Can Bert tell just by feeling that the sponge is wet?" (O’Neill, Astington, \& Flavell, 1992; see also Pillow, 1989). Yet their ability to select the sensory action appropriate for their informational goal is fragile. For example, O’Neill et al. (1992) asked 3- to 5-year-olds to decide whether to look at or touch a hidden object in order to determine its color or texture. Both 3- and 4-year-olds showed a preference to feel instead of a discriminative use of looking to learn color and feeling to learn texture. Using the same hidden object paradigm, Perner and Ruffman (1995), on the other hand, found that children gave preference to looking. Together, these studies suggest that while 4-year-olds may understand the sufficiency of actions such as looking and touching in giving rise to knowledge they may have difficulty isolating the action that has to be performed in order to gain different types of knowledge (see also O'Neill \& Chong, 2001; Robinson et al., 1999; Robinson, Haigh, \& Pendle, 2008).

The limitations apparent in 4-year-olds' action selection suggest that they may also have difficulty selecting between direct experience and asking others. Nevertheless, their sensitivity to cues that help efficiently integrate information from direct experience and testimony (e.g., Bonawitz et al., 2011; Robinson et al., 1999) suggests that they may attend to cues that are predictive of the potential efficacy of looking and asking. One such cue is whether the information they seek is about visible or invisible properties. Direct observation provides immediate and reliable knowledge about appearance but not about unobservable properties. In contrast, expert knowledge is obtained through special training and experience and goes beyond the visible in a domain (Lutz \& Keil, 2002). Thus, asking an expert provides access to invisible information - such as general and hidden properties - better than inductive inference from limited observations (Gelman, 2009).

To examine 4- and 6-year-olds' ability to choose between looking and asking, we presented them with a choice between asking a knowledgeable person and looking at the target of the question (an object or a person) in two conditions. In the visible information condition, children were presented with the goal of finding a visually observable property (e.g., hair color and dress). In the invisible information condition, children were presented with the goal of finding an invisible property of either an individual or group (e.g., abilities, preferences, and relationships). If children apply looking and asking appropriately, we expected them to choose to look to find out visible information and to ask available experts to find out invisible information.

The research involved 4- and 6-year-old children. As shown, 4-year-olds are limited in their ability to select an action to achieve a goal. Yet they also display substantial skill in handling many aspects of information gathering, including integrating self- and other-generated information and selecting among informants. In addition, a recent study shows that when considering others' knowledge 4-year-olds associate looking with knowledge of appearance and expertise with knowledge of invisible properties. Specifically, 4-year-olds attended to whether potential informants had had visual access to an object when it had to be identified on a picture and to informants' expertise, as revealed by past testimony, when the object had to be labeled (which is an invisible property, Brosseau-Liard \& Birch, 2011). Six-year-olds represent the upper boundary of the age range studied in the informational access and information gathering literatures and usually excel at these tasks. Thus, this age group provides a standard against which 4-year-olds' performance can be evaluated.

\section{Experiment 1}

Children in this experiment had to find visible and invisible information about animal-like figurines called "moozles." To maximize the salience of the distinction between visible and invisible conditions, the visible information concerned particular moozles while the invisible information concerned moozles in general. 
Children were given the choice between looking directly at a moozle and asking a "moozle expert."

\section{Method}

Participants. Twenty-four 4-year-olds ( $M=52$ months, $S D=3$ months; 11 boys and 13 girls) and twenty-four 6-year-olds ( $M=78$ months, $S D=4$ months; 12 boys and 12 girls) participated in the study. The children came from predominantly middleclass, Caucasian families. Four other children (two 4-year-olds and two 6-year-olds) were excluded because of unwillingness to engage with the moozle expert (who was a confederate in the study) during the warm-up period.

Materials. Eight moozles were created for the experiment (Figure 1). Each moozle was unique as a result of counterbalancing whether moozles had stripes or spots on their bodies, whether they carried a feather or a flower, and whether they wore a hat. Each had different hair color. Eight different colored buckets were used to hide the moozles. A pair of walkie-talkies was used for communication between the child and the moozle expert.

Table 1 shows the questions that were used in the study. Half were about visible properties (visible information condition) and half about invisible properties (invisible information condition). The questions in the visible condition were about a particular moozle and were formulated using a definite noun phrase, e.g., "What color is the moozle's hair?" The questions in the invisible condition were formulated using a generic phrase, e.g., "Do moozles like pizza?" By age 4, children understand that generics refer to kinds and information that may not be directly observable (Gelman \& Bloom, 2007). Thus, generics may further highlight the relevance of the asking action.

Procedure. The task began by the experimenter introducing a friend who was a "moozle expert." The moozle expert wore a yellow lab coat with a picture of a moozle on it. Following Taylor, Esbensen, and Bennett's (1994) description of an "expert" (see also Koenig \& Jaswal, 2011), children were told that most people do not know about moozles and that the expert had learned about them in school, read many books about them, and had even written a book about moozles: "She knows more about moozles than any of her friends, including me! We call her a moozle expert because she knows so much about moozles!"

After children agreed to play a "moozle game," they were shown the moozles, which were placed on a separate table. Chil-

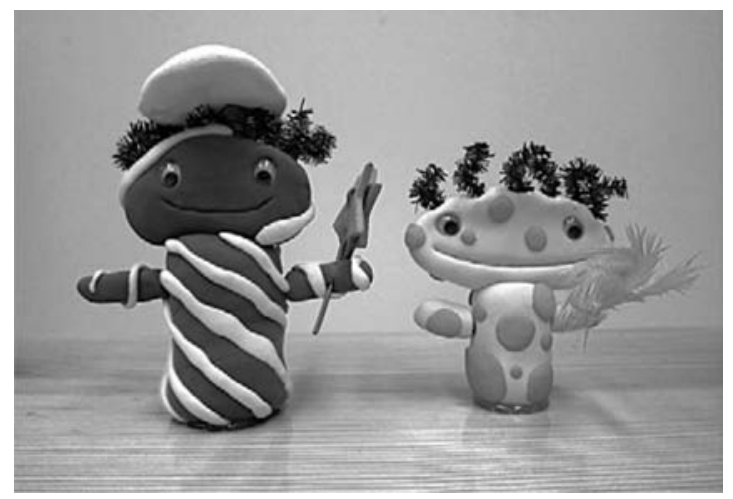

Figure 1. Example of the moozle figurines used in Experiment 1.
Table 1

Stimuli in Experiment 1

\begin{tabular}{ll}
\hline \multicolumn{1}{c}{ Visible condition } & \multicolumn{1}{c}{ Invisible condition } \\
\hline $\begin{array}{l}\text { What colour is the moozle's hair? } \\
\text { Does the moozle have stripes or } \\
\text { spots? }\end{array}$ & Do moozles like pizza? \\
$\begin{array}{l}\text { What does the moozle carry in its } \\
\text { hand? }\end{array}$ & Can moozles read books? \\
\begin{tabular}{l} 
Is the moozle wearing a hat? \\
\hline
\end{tabular} & What makes moozles sick? \\
\hline
\end{tabular}

dren's attention was directed to the variability in the moozles' visible features: "See, the moozles all have different colored hair! What color is this one? ... And this one? ... Some have stripes and others have spots, and some wear hats and some do not, and they all carry something different. What is this one carrying?" After children examined the moozles, the moozles were covered with the buckets and the moozle expert left the room "so that the game can begin" saying that she would be nearby and happy to answer any questions the child might have about moozles. ${ }^{1}$ The experimenter and the child then sat at a computer a few steps away from the moozle table.

The experimenter explained the computer makes up questions about the moozles, and the task is to find out the answers. Children were told not to guess (as this was the first time they encountered moozles) and that sometimes it is best to look at the moozles with their eyes and sometimes it is best to ask the moozle expert. The experimenter then demonstrated how to use the walkie-talkie by engaging in a brief conversation with the moozle expert. Following the demonstration, children also asked the moozle expert questions using the walkie-talkie. After three question-answer turns, the game began. Four children who did not direct any questions to the moozle expert after several prompts were replaced. The experimenter operated the talk button of the walkie-talkie throughout the experiment (children were welcome to help).

The experimental task consisted of eight trials. Each trial began with the computer presenting one of the questions shown in Table 1 while children viewed a picture of a gray moozle on the screen. Children were asked to repeat the question to make sure they correctly understood and remembered what they had to find out. If they did not repeat the question or if they modified it, the experimenter reiterated the question and children were asked again to repeat it. Then pictures of a gray bucket and a gray walkie-talkie appeared on the screen and children were asked whether they wanted to use their eyes and look under a bucket or ask the moozle expert to find out the answer to the question. Children indicated their choice verbally or by touching the icons on the screen so as not to conflate their choices with the performance demands of the looking and asking actions (O'Neill et al., 1992; Robinson et al., 2011). If the child selected the bucket (to look), a colored bucket appeared on the screen to indicate under which bucket the child

\footnotetext{
${ }^{1}$ We piloted the procedure with the moozle expert staying in the room and allowing children to direct the questions to her directly if they chose to ask. This procedure, however, was unsuccessful in eliciting asking. Hence, we adopted the present approach guided by studies on children's ability to choose between looking and touching in which children indicated their choice symbolically (O'Neill et al., 1992; see also Robinson, Butterfill, \& Nurmsoo, 2011).
} 
should look. The experimenter led the child to the table, lifted the bucket, let the child look at the moozle for about $10 \mathrm{~s}$, and replaced the bucket. If the child selected the walkie-talkie (to ask), a picture of the expert in color appeared on the screen and the experimenter activated the walkie-talkie for the child. No child showed difficulty restating the question at this point. Previous research suggests that children may not trust previously ignorant or inaccurate speakers (e.g., Koenig \& Harris, 2005; Koenig \& Jaswal, 2011). Thus, to make sure that children were not discouraged from asking, the moozle expert answered informatively and confidently all questions she was asked regardless of whether they were about visible or invisible properties. Once the chosen action was performed, the experimenter repeated the question and recorded the child's response without providing feedback.

The eight questions were presented in random order. The order of the look and ask options in the test question and the position of the bucket and walkie-talkie pictures on the screen were counterbalanced across children.

At the end of the game, children were asked a question to check if they remembered that the confederate was a moozle expert: "Do you remember what I told you about my friend Tara? What's special about her?" All but four children (three 4-year-olds and one 6-year-old) identified the confederate as a moozle expert. Excluding them from the analyses did not lead to significant changes in the results and the analyses reported below include the entire sample.

\section{Results}

Preliminary analyses showed no effect of gender and the order of the look and ask options in the questions. There was also no significant effect of trial in either condition suggesting that no learning occurred over the course of the study. These variables are not considered further. Item analyses revealed that 6-year-olds' performance on one of the invisible items ("Can moozles read books?") was markedly different from their performance on the other items in this condition (1.5 SD away from the mean). This item was excluded from the data. ${ }^{2}$

The average proportion of times children chose to look in the visible and invisible conditions is displayed in Figure 2. The scores were analyzed using a repeated-measures analysis of variance with age (4 vs. 6) as a between-subjects factor and condition (visible vs. invisible) as a within-subject factor. Children were significantly more likely to choose to look in the visible $(M=.84, S D=.16)$ than in the invisible condition $(M=.4, S D=.25), F(1,46)=$ 75.968, $p<.001, \eta_{\mathrm{p}}^{2}=.6$. In addition, 4-year-olds were significantly more likely to choose to look than 6-year-olds $(M=.69$, $S D=.23$ for 4-year-olds; $M=.54, S D=.23$ for 6-year-olds), $F(1$, 46) $=5.39, p=.025, \eta_{\mathrm{p}}^{2}=.11$. Finally, there was an interaction between age and condition, $F(1,46)=23.89, p<.001, \eta_{\mathrm{p}}^{2}=.34$. Follow-up paired $t$ tests showed that the likelihood of choosing to look was higher in the visible than the invisible condition for both 6-year-olds, $t(23)=10.84, p<.001$, and 4-year-olds, $t(23)=$ $2.229, p=.04$. However, the effect size, as measured by Cohen's $d$, was greater for the older children (2.99 vs. 0.56).

We also evaluated children performance in each condition relative to chance (.5). As Figure 2 suggests, 6-year-olds performance was different from chance in both conditions. They chose to look above chance in the visible condition, $M=.88, S D=.15, t(23)=$

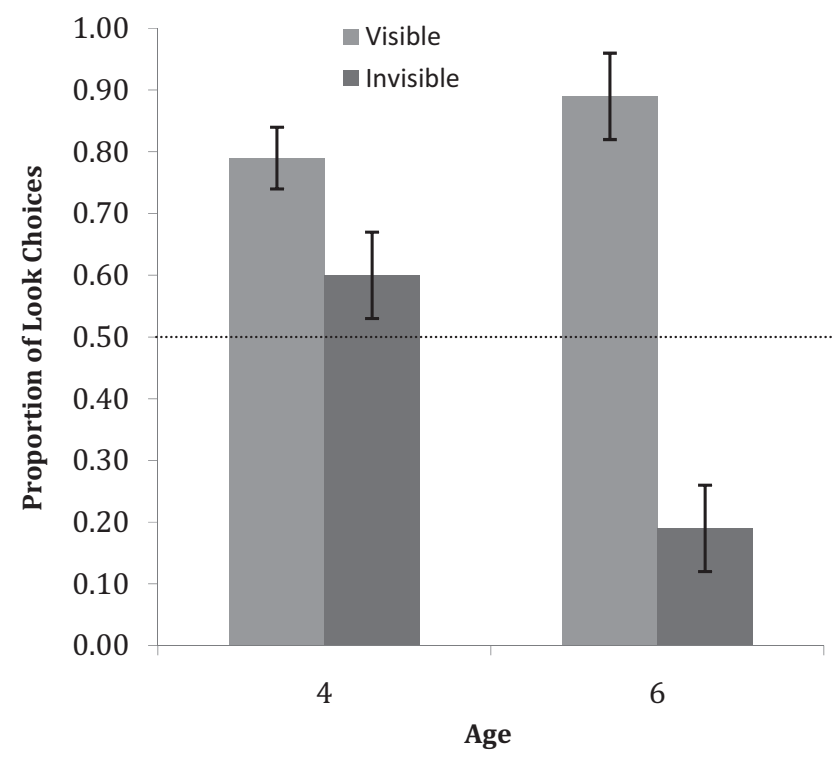

Figure 2. Mean proportion of choices to look in Experiment 1 by age and condition. Error bars represent $\pm 1 S E$.

23.84, $p<.001$, and below chance in the invisible condition (i.e., they chose to ask), $M=.19, S D=.29, t(23)=-5.1, p<.001$. Four-year-olds chose to look above chance in the visible condition, $M=.79, S D=.27, t(23)=5.243, p<.001$, and did not make a consistent choice in the invisible condition, $M=.6, S D=.39$, $t(23)=1.212, p=.24$. Thus, while both age groups discriminated between the two conditions, only 6-year-olds selected the appropriate action in each.

\section{Discussion}

Experiment 1 had two main findings. First, as early as age four, children did not treat looking and asking equivalently across information gathering tasks. Instead, they were more likely to look when pursuing visible than invisible information. This finding complements existing studies on children's learning and information gathering (e.g., Bonawitz et al., 2011; Jaswal et al., 2010; Koenig \& Harris, 2005; O’Neill et al., 1992; Robinson et al., 1999) to reveal an early differentiation of the uses of one's own perception and expert testimony.

Second, even though both age groups were more likely to look when pursuing visible than invisible information, only 6-year-olds

\footnotetext{
${ }^{2}$ Examining children's repetitions showed that about $33 \%$ of the children paraphrased this item, "Can moozles read books?" as "Do moozles read books?" or "Is it reading a book?" suggesting that they may have focused on reading as an activity rather than ability. A focus on ability was crucial for our predictions. A factor that may have contributed to the lack of salience of "can" is that all questions in this study were asked with rising intonation, thus emphasizing their endings. Performance on an analogous item in Experiment 2, "Can Peter swim?" which was asked with an emphasis on "can," converged with children's performance on the other invisible items in that study. (Including "Can moozles read books?" 6-yearolds chose to ask $68 \%$ of the time in the invisible condition, which was still different from chance, and 4-year-olds chose to ask still $40 \%$ of the time $[n s]$. The other main results were also not affected.)
} 
reliably chose to ask to obtain invisible information. Four-yearolds tended to look in both conditions. They showed this preference despite the fact that they remembered that the confederate was a moozle expert, they were not shy or unable to use the walkie-talkie, the moozle expert answered all questions she was asked, and the invisible questions incorporated generic forms that further highlighted the relevance of expertise.

Nevertheless, the study raises a number of questions. First, it is unclear whether the specific-generic distinction, which covaried with condition (visible-invisible), is necessary for children to show discrimination between the conditions. Second, the fact that the moozle expert answered all questions if asked may have diluted the distinction between the conditions for some children and exaggerated it for others.

Third, it is unclear whether 4-year-olds' preference to look is specific to this study or reflects a more global bias. On the one hand, it is plausible that this preference is driven by factors specific to this study. For example, 4-year-olds may have been drawn to the three-dimensional toy-like moozles and chosen to look due to their attraction toward playing with the moozles. In addition, the novelty of the concept of a "moozle expert" may have undermined 4-year-olds' performance. Even though previous research has shown that 4-year-olds make appropriate generalizations with novel expert concepts (e.g., "eagle expert") their performance is generally stronger if experts are familiar (e.g., "doctor"; Lutz \& Keil, 2002). Another possibility is that young children associated greater effort with activating the walkie-talkie and articulating the questions (even though the experimenter operated the walkie-talkie and they had repeated the questions) than with walking to the table on which the moozles were placed and waiting for the bucket to be lifted. Thus, they may have chosen to look because it was easier.

On the other hand, it is also plausible that 4-year-olds' preference to look is associated with a more global bias. In particular, 4-year-olds may have greater confidence in knowledge derived from direct experience than knowledge derived from others' testimony. For example, a statement that is inconsistent with beliefs currently held by the child is more likely to affect beliefs the child has acquired from a knowledgeable other than beliefs that are identical in content but the child has acquired through direct experience (Robinson, Haigh, \& Nurmsoo, 2008). In Experiment 2, we attempted to address several of these questions.

\section{Experiment 2}

The principal goal of Experiment 2 was to provide a conceptual replication of Experiment 1 and clarify its results. We removed generic forms that may have helped both younger and older children discriminate between the visible and invisible informational goals. Instead, all questions were about specific individuals. In addition, the informant claimed ignorance if asked a visible information question instead of answering informatively. Both of these changes aimed to clarify the extent to which children discriminate between looking and asking in information gathering.

We also changed a number of features that could have biased children to look in Experiment 1. In particular, we changed the actions associated with children's choices to minimize potential differences in effort or attractiveness the two options may have presented. In the present study there were no walkie-talkies and children did not have to either articulate the questions or move. In addition, we used two-dimensional stimuli and an expert concept that was familiar. Participants had to find visible and invisible properties of children, and they could either ask a friend of these children or look at the children's pictures. By preschool, children clearly distinguish between friends and nonfriends, spend much more time with the former, and their interactions with friends are characterized by a greater degree of cooperation and mutuality in comparison to interactions with nonfriends (Hartup \& Stevens, 1997; Newcomb \& Bagwell, 1995). Children are more likely to share ideas and feelings with friends (Dunn, 2004; Howes, 2009; Hughes \& Dunn, 1998), which, along with the greater amount of time spent playing together, is likely to result in an "expertise" about one another. Indeed, children see friends as more knowledgeable than nonfriends about one's secrets, preferences, and goals (e.g., "what I want to be when I grow up"; Burton \& Mitchell, 2003).

While attempting to clarify the extent to which children appropriately apply looking and asking to pursue their informational goals, we also examined children's confidence in the information they gathered as differential confidence in information sources may bias their action choices. Thus, at the end of each trial, children were asked how confident they were that the answer they had provided to the question was correct.

\section{Method}

Participants. Twenty-four 4-year-olds ( $M=53$ months, $S D=2.9$ months, 10 girls and 14 boys) and twenty-four 6-yearolds ( $M=78$ months, $S D=3.3$ months, 12 girls and 12 boys) participated in the study. The children were recruited from the same pool as the children in Experiment 1.

Materials. Two sets of $8 \times 12 \mathrm{~cm}$ index cards were used in this study. The image set consisted of nine cards (five girls and four boys). One of the girls-Jennie — served as the informant in the study and the remaining children were Jennie's friends. On one side of each card was a stylized picture of a child and on the other side was the child's name. Three properties were counterbalanced across the eight children that represented Jennie's friends: whether they wore a hat or not, whether they wore pants or shorts, and whether they carried bags or balloons. Clothing and shoe color were unique for each child. Another set of eight cards was used to present the questions. These cards had Jennie's friends' names on one side and a question on the other (see Table 2). Half of the questions were about directly observable properties (visible con-

Table 2

Stimuli in Experiment 2

\begin{tabular}{ll}
\hline \multicolumn{1}{c}{ Visible condition } & \multicolumn{1}{c}{ Invisible condition } \\
\hline What color is Emma's shirt? & $\begin{array}{c}\text { What does Billy want to be } \\
\text { when he grows up? }\end{array}$ \\
Is Tom wearing shorts or pants? & Can Peter swim? \\
What does Lily carry in her hand? & $\begin{array}{c}\text { Does Anna know how to speak } \\
\text { French? }\end{array}$ \\
Is Joe wearing a cap? & What is the name of Sarah's \\
& school teacher? \\
\hline
\end{tabular}


dition) and half about properties that cannot be directly observed (invisible condition).

Procedure. The study began by the experimenter spreading the pictures of Jennie and her friends in front of the participant. As in Experiment 1, children's attention was directed to the variability in the targets' appearance (e.g., "See, some of them are boys and some are girls. Some are wearing hats and others are not."). The cards were then collected in a pile and turned over so that the pictures faced down. Thus, participants could not match the names on the cards with the images. The experimenter showed the question card set and explained that the goal of the game was to find the answers to questions about Jennie's friends. To obtain an answer, children had the option to either look at the picture of the child the question was about or to ask Jennie.

Participants were then shown Jennie's picture on the computer monitor. The game started with a brief warm up during which Jennie introduced herself to the child and then asked several simple everyday questions, e.g., "Hi, I'm Jennie, nice to meet you! How are you doing today? ... Did you have a good day at school today?" (All utterances were prerecorded.) This part of the procedure was similar to the way in which rapport was built between the moozle expert and the children in Experiment 1. Most children spontaneously responded to these questions and the rest did so with a prompt from the experimenter. Jennie also asked whether children remembered how to play the game. Regardless of the response, she reiterated that they would be asked questions and, to figure out the answers, they had to choose between looking at a picture and asking her.

Each trial started with the experimenter drawing a question card and reading the question on it. Children were asked to repeat the question to make sure they remembered it. If they did not or if they paraphrased the question, the experimenter reiterated it and children were asked to repeat it again. Children were then asked whether they wanted to look at a picture of the person the question was about or ask Jennie. If children chose to look, the experimenter picked the appropriate card from the image pile and presented it to the child for about $10 \mathrm{~s}$. If children chose to ask, the experimenter pressed a button and children heard a response. When children chose to ask Jennie about an invisible property, she responded informatively. When they chose to ask her about a visible property, she said that that she did not know. Thus, similar to Experiment 1, the experimenter facilitated children's choices; however, in contrast to Experiment 1, children were not required to physically displace themselves after they chose to look, or articulate a question after they chose to ask.

After children executed the chosen action, the experimenter repeated the question and recorded the child's answer. Unless children answered "I don't know," they were asked to indicate how confident they were in their answer, "a little bit sure" or "very sure." The experimenter spread her arms all the way to indicate "very sure" and about $5 \mathrm{~cm}$ apart to indicate "a little bit sure."

The trials were randomized for each child. The order of "look" and "ask" in the action selection question and of "very sure" and "a little bit sure" in the confidence question was counterbalanced across children. Children received no feedback on their answers.

At the end, the children were asked whether and how Jennie knew the children in the pictures. All but two 4-year-olds and two 6 -year-olds responded that Jennie and the children in the pictures were friends. Excluding these children from the analyses did not lead to significant changes in the results so the analyses reported below include the entire sample.

\section{Results}

Action choice. The proportion of times children chose to look in each condition is displayed in Figure 3. Preliminary analyses showed no effect of gender or item so these variables are not considered further. The data were analyzed as a function of age and condition. The analysis showed no effect of age, $F(1,46)=$ 2.453, $p=.12, \eta_{\mathrm{p}}^{2}=.05$. As in Experiment 1, children choose to look significantly more often in the visible $(M=.59, S D=.23)$ than the invisible condition $(M=.29, S D=.24), F(1,46)=$ $36.125, p<.001, \eta_{\mathrm{p}}^{2}=.44$. There was also a significant interaction between age and condition, $F(1,46)=8.315, p=.006 \eta_{\mathrm{p}}^{2}=$ .15. Follow-up $t$ tests revealed that both younger and older children discriminated between the conditions, showing a greater tendency to look for visible than invisible information, $t(23)=6.225, p<$ .001 for 6-year-olds, $t(23)=2.221, p=.036$ for 4-year-olds. However, the effect size was larger for 6-year-olds than 4-yearolds (Cohen's $d=1.37$ vs. 0.46 ).

Children's performance in each condition was also compared to chance (.5). Six-year-olds' performance was again different from chance in both conditions. They chose to look significantly above chance in the visible condition, $M=.73, S D=.31, t(23)=3.598$, $p=.002$, and significantly below chance in the invisible condition (i.e., they chose to ask): $M=.28, S D=.33, t(23)=-3.173, p=$ .004 . Four-year-olds chose to look at chance level in the visible condition, $M=.46, S D=.33, t(23)=0.6, p=.5$, and significantly below chance in the invisible condition, i.e., as 6-year-olds, they chose to ask: $M=.29, S D=.33, t(23)=-3.122, p=.002$.

In contrast to Experiment 1, when trial order was included in the analysis (coded 1 to 4 for each condition), we found evidence for learning. Specifically, in addition to replicating the significant effects reported above, a generalized estimating equations model showed an interaction effect between trial order and condition,

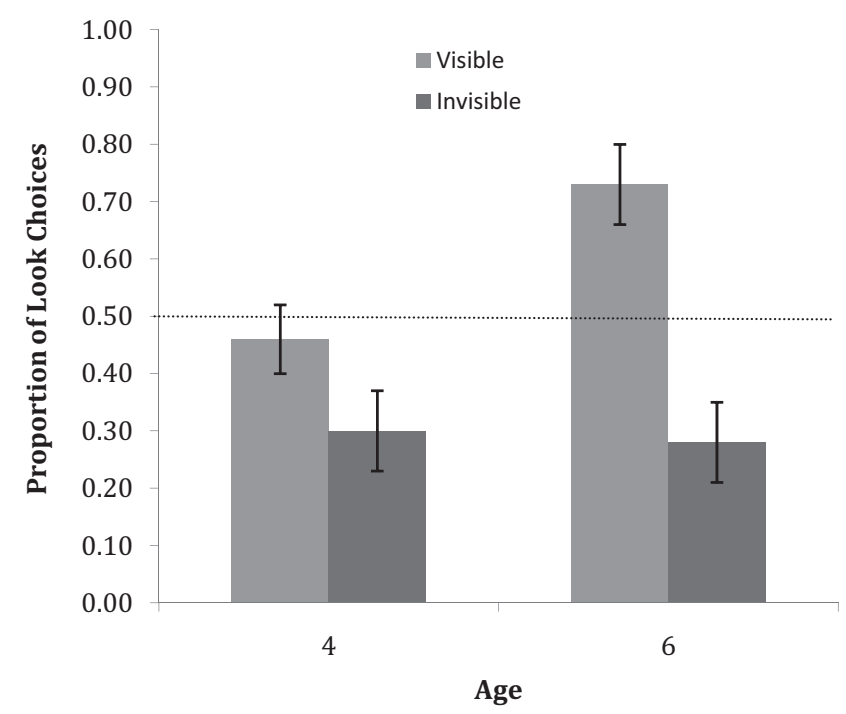

Figure 3. Mean proportion of choices to look in Experiment 2 by age and condition. Error bars represent $\pm 1 S E$. 
reflecting greater discrimination between conditions with time, Wald $\chi^{2}(3)=9.396, p=.024$. Additional analyses revealed that 6-year-olds were marginally more likely to look for visible information as trials advanced, Wald $\chi^{2}(1)=2.880, p=.09$, by linear contrast, and significantly more likely to ask for invisible information as trials advanced, Wald $\chi^{2}(1)=4.463, p=.035$, by linear contrast. The effect of trial order was not significant in the 4-yearolds' data.

Confidence. We examined whether the type of a search action influenced children's confidence in the answers they provided. Only trials on which children chose the appropriate action were included the analysis. In these cases, children uniformly provided the correct answer after looking and repeated Jennie's answer after asking. (When they did not choose the appropriate strategy, children made up an answer $70 \%$ of the time and answered "I don't know" $30 \%$ of the time.)

Confidence was coded from the verbal responses because children always answered verbally. High confidence was coded as 1 and low as 0 . The data were submitted to a linear mixed model analysis where age (4 vs. 6) and action choice (look vs. ask) were modeled as fixed effects. Six-year-olds $(M=.90, S D=.24)$ were more confident than 4-year-olds $(M=.66, S D=.36), F(1,46)=$ $6.341, p=.015$. But, in general, children were just as confident in information obtained through looking $(M=.82, S D=.35)$ as in information obtained through asking $(M=.77, S D=.33), F(1$, 266) $=0.61, p=.43$. The interaction between age and action choice was not significant, $F(1,266)=0.36, p=.55$.

\section{Discussion}

Experiment 2 replicated the key findings of Experiment 1. As in Experiment 1, both groups discriminated between the visible and invisible conditions and showed higher rates of looking to obtain visible than invisible information. In addition, 6-year-olds performed better than 4-year-olds. They selected the appropriate action in both condition while 4-year-olds did so only in the invisible condition.

Experiment 2 implemented a number of changes aimed to address questions about the findings in Experiment 1. Perhaps most important was the question of how well both younger and older children discriminate between looking and asking given that in Experiment 1 the specific-generic distinction was superimposed on the visible-invisible distinction and that the moozle expert answered all questions. Children in the present study discriminated between the visible and invisible conditions to about the same extent as the children in Experiment 1, thus minimizing concerns about this central finding. Although caution is needed in drawing conclusions about any single factor, Experiment 2 indicates that the contrast between specific and generic information is not necessary for either younger or older children to discriminate between visible and invisible informational goals.

In contrast to Experiment 1, where 4-year-olds showed a bias to look, in the present study they showed a bias to ask. Thus, taken together, our findings are inconsistent with a global bias to either look or ask at age four. Nevertheless, 4-year-olds' preference to ask in the present study was just as unexpected as their preference to look in Experiment 1. Reviewing the methodology of the present study brings attention to at least two features that may have had an unforeseen effect. First, 4-year-olds may have found it less engaging to look at a picture than to receive a response from the informant. Given that both choices entailed looking at stylized, previously seen pictures, Jennie's responding may have increased the appeal of asking. Second, the presentation of the informant as someone's friend may have made her more likeable or trustworthy for 4-year-olds resulting in greater likelihood that they interact with her.

The present study also suggests that 4- and 6-year-olds' confidence in information obtained through looking is unlikely to be radically different from their confidence in information obtained through asking. This finding contrasts research suggesting that children have greater confidence in knowledge obtained from direct experience than from the testimony of others (Robinson, Haigh, \& Nurmsoo, 2008). However, it is consistent with findings such as that children confer similar ontological status to entities that they see (e.g., cats and trees) and some of the entities that they learn about exclusively through testimony (in particular scientific entities like germs, vitamins, and oxygen; Harris, Pasquini, Duke, Asscher, \& Pons, 2006). The inconsistency with the findings of Robinson et al. (2008) may be due to an array of methodological differences. It is especially notable that their participants always formed beliefs about object properties that could be directly apprehended through visual or tactile exploration (e.g., color). Thus, it is possible that their participants' greater confidence in beliefs from direct experience was due to the fact that direct experience was the more appropriate information source given the task.

In view of research showing that children do not choose as informants speakers who have displayed a lack of knowledge (e.g., Koenig \& Harris, 2005), it may be surprising that 4-year-olds preferred to ask. A potential reconciliation is offered by research showing that children's trust in speakers who have been inaccurate is influenced by whether the speakers' errors could be excused (Nurmsoo \& Robinson, 2009a). In the present study, the transience of a person's appearance may have allowed children to justify Jennie's ignorance of the answers to the visible questions while her answers to the invisible questions may have confirmed her expertise as a friend. Thus, her verbal behavior may have appeared as calibrated to her knowledge. In contrast, in Koenig and Harris (2005) children were presented with an apparently competent adult English speaker who mislabeled common objects or claimed ignorance of their names. Such behavior may be harder to explain. Future research should examine directly whether the justifiability of ignorance (just as the justifiability of error) is related to children's subsequent trust in ignorant informants.

Of note, Jennie's expressions of ignorance may also relate to the learning effects in this study. An informant's expression of ignorance marks failure to find an answer and potentially signals errors to the information seeker more clearly than uninformative visual exploration (the only cue to error in Experiment 1), as there is an interruption of the information flow. Thus, rather than discourage asking, an informant's expression of ignorance may lead to more discriminating information seeking.

\section{General Discussion}

Children actively search for information: They look, explore, and ask questions. In two experiments, we found that as early as age four, children choose to look and ask with different probability in different situations. Both experiments also showed a marked 
improvement in the ability to select the optimal action with age. Six-year-olds chose to look for a visible property and to ask for an invisible property above chance in both experiments. Four-yearolds, in contrast, showed preference for looking in Experiment 1 and asking in Experiment 2, even though they discriminated between the visible and invisible conditions in each experiment. Taken together, these findings reveal an early emerging understanding of the goal-dependent efficacy of different information gathering actions. They also add to other research suggesting that mastering the art of learning-learning to learn-is a process that extends through and possibly beyond early childhood (e.g., Heyman \& Legare, 2005; Mills, Legare, Bills, \& Mejias, 2010; Robinson et al., 2011).

The present findings contribute to understanding the role children play in the construction of their knowledge. Previous research has extensively examined how children integrate information from testimony and direct experience (e.g., Bonawitz et al., 2011; Buchsbaum et al., 2011; Burtler \& Markman, 2012; Chouinard, 2007; Frazier et al., 2009; Jaswal, 2004, 2010; Tizard \& Hughes, 1984) and how children select between different informants (Birch et al., 2008; Fitneva, 2010; Jaswal \& Neely, 2006; Koenig \& Harris, 2005; Mascaro \& Sperber, 2009). Yet in these studies, either the information-gathering action was chosen for children (because it was the efficacy of their subsequent decisions that was being examined), or pedagogical cues directed children's attention to the appropriate action choice. The present studies went further to examine how children decide whether to look or to ask when seeking information. Our findings show that by age four children attend to factors that may influence the effectiveness of an information-gathering action such as the visibility of the information being sought. Although 4-year-olds' performance was not as robust as 6-year-olds', they discriminated between visible and invisible informational goals in two quite different studies. Moreover, their performance did not depend on simple but powerful linguistic cues, such as generic forms.

The present findings also establish that neither 4- nor 6-yearolds treat knowledge from testimony or direct experience as preferable across situations. In both studies 6-year-olds looked for visible and asked for invisible information. Four-year-olds, on the other hand, were biased toward looking in one study and toward asking in the other. Further support for the absence of a global preference for an information-gathering action comes from the similar levels of confidence children showed in beliefs that had originated from direct experience and testimony (Experiment 2). These findings are consistent with theories and evidence suggesting that direct experience and the testimony of others have similar epistemological status and psychological consequences (Harris, 2002a, 2002b; Harris \& Koenig, 2006). Taken together, they call into question strong theories about either empiricist or credulity biases in early childhood learning.

Age differences in the strength with which children discriminated between the visible and invisible conditions may indicate limitations in 4-year-olds' representation of the goal-dependent efficacy of information gathering actions. We learn through experience what kinds of information looking and asking are best at providing, and it is plausible that the lessons from this experience remain incomplete at age four. However, differences in experience alone are insufficient to explain 4-year-olds' biases in the two studies. Importantly, bias has been observed in other studies where children have to select the appropriate action given a goal (O'Neill et al., 1992; Perner \& Ruffman, 1995; Robinson, Haigh, \& Pendle, 2008). Bias also appears when children have to integrate information from testimony and direct experience and decide what to believe (e.g., Ceci \& Bruck, 1993, 2006; Field, 1987; Jaswal, 2010; Jaswal et al., 2010; Melnyk et al., 2007). While the present studies were not designed to examine biases in children's decision making, they clearly highlight the need for further research in this area.

We can eliminate some potential reasons for 4-year-olds' biases. First, it is unlikely that familiarity affected their willingness to approach the expert because in both studies the informant was someone who was just presented to them. Second, children's preferences were probably not driven by visual appeal. In Experiment 2, Jennie and her friends were matched in size, facial expression, and clothing. Finally, the similarity in children's confidence in information from testimony and direct experience suggests that their preferences did not derive from global epistemic commitments favoring one of the actions over the other.

In seeking a framework that can provide insight into what the explanation of 4-year-olds' biases is rather than what it is not, we turn to the design factors we discussed with respect to each study and the idea that information gathering is often embedded in broader activities, e.g., entertaining, playing, building a relationship. Four-year-olds in our studies showed a different action preference in each study, indicating that that preference was locally determined. It is possible that they are less able to coordinate multiple nested goals or do not differentiate the goal of information gathering from other activity goals as well as 6-year-olds. Thus, they may be drawn to attractive and salient features of the environment that, even from the point of view of 6-year-olds, are largely irrelevant to the success of information gathering. Or, the goals they associate with the broader activity may bias their choice of action more strongly than their informational goals. Indeed, as customary, the studies were introduced to children as "a game," and they may have turned to the moozles and Jennie because they saw them as the most likely objects of play.

Several lines of research independently suggest that the goal of information gathering may be articulated relatively weakly for preschoolers. For instance, 4- to 5-year-old children who showed sensitivity to an informant's experience when deciding whether to consult and accept her suggestions, failed to do so when they had to elicit answers (children simply had to lift a receiver to indicate an intention to ask, not generate questions, Robinson et al., 2011). In addition, the literature on suggestibility reveals willingness to accept false suggestions contained in questions (technically a means for eliciting information; see Ceci \& Bruck, 1993; Fitneva, 2012). Also related to question asking, research reveals that in a number of contexts only a relatively small part of preschoolers' questions can be categorized as information-seeking (in the sense of being directed by an ignorant person to a person who likely knows the answer, e.g., Sinclair \& Van Gessel, 1990; see Shatz, 1979 , for similar findings in parents' questions). Thus, especially for preschoolers, information gathering may have a quality of transparency even though children are incessantly-and successfully-engaged in it. Cognitive development in early childhood is often characterized as moving from having knowledge or skill to being able to reflect on it (Piaget, 1929; Robinson, Haigh, \& 
Pendle, 2008; Vygotsky, 1929; Zelazo, Müller, Frye, \& Marcovitch, 2003). Information gathering may be no exception.

Future research should better characterize 4-year-olds ability to select between testimony and direct experience in different information gathering situations. Assuming that the biases they showed relate to the coordination of informational and other goals suggests that a key question for future research is how to foreground informational goals. Looking and asking inherently orient children to different aspects of the world. Thus, matching these forms of information gathering for salience and attractiveness could be challenging. Making the task more abstract, e.g., by eliminating action execution, might allow 4-year-olds to perform better (Apperly \& Carroll, 2009; Carlson, Davis, \& Leach, 2005; Jaswal et al., 2010). Future research is also needed to gain a better understanding of the developmental changes we observed. Here, the account outlined above suggests that children's ability to disassociate information seeking from on-going activities would be associated with better ability to select a search action.

\section{Conclusion}

Many of the skills and beliefs children develop result from serendipitous observation of people, objects, and events, and from deliberate instruction by adults. But children also actively explore the environment and seek out the testimony of others. Our studies show that both 4- and 6-year-olds are sensitive to the different efficacy of looking and asking in different information gathering situations, albeit 4-year-olds often fail to systematically select the appropriate action and instead show a bias to look or to ask. Children's locally driven preferences largely disappear by age six suggesting that harnessing the power of action in the service of information gathering is a major accomplishment of early childhood.

\section{References}

Apperly, I. A., \& Carroll, D. J. (2009). How do symbols affect 3- to 4-year-olds' executive function? Evidence from a reverse-contingency task. Developmental Science, 12, 1070-1082. doi:10.1111/j.1467-7687 .2009.00856.x

Baldwin, D. A., \& Moses, L. J. (1996). The ontogeny of social information gathering. Child Development, 67, 1915-1939. doi:10.2307/1131601

Birch, S. A. J., Vauthier, S. A., \& Bloom, P. (2008). Three- and four-yearolds spontaneously use others' past performance to guide their learning. Cognition, 107, 1018-1034. doi:10.1016/j.cognition.2007.12.008

Bonawitz, E., Shafto, P., Gweon, H., Goodman, N. D., Spelke, E., \& Schulz, L. (2011). The double-edged sword of pedagogy: Instruction limits spontaneous exploration and discovery. Cognition, 120, 322-330. doi:10.1016/j.cognition.2010.10.001

Brosseau-Liard, P. E., \& Birch, S. A. J. (2011). Epistemic states and traits: Preschoolers appreciate the differential informativeness of situationspecific and person-specific cues to knowledge. Child Development, 82 , 1788-1796. doi:10.1111/j.1467-8624.2011.01662.x

Buchsbaum, D., Gopnik, A., Griffiths, T. L., \& Shafto, P. (2011). Children's imitation of causal action sequences is influenced by statistical and pedagogical evidence. Cognition, 120, 331-340. doi:10.1016/j .cognition.2010.12.001

Burtler, L. P., \& Markman, E. M. (2012). Preschoolers use intentional and pedagogical cues to guide inductive inferences and exploration. Child Development, 83, 1416-1428. doi:10.1111/j.1467-8624.2012.01775.x
Burton, S., \& Mitchell, P. (2003). Judging who knows best about yourself: Developmental change in citing the self across middle childhood. Child Development, 74, 426-443. doi:10.1111/1467-8624.7402007

Callanan, M. A., \& Oakes, L. M. (1992). Preschoolers' questions and parents' explanations: Causal thinking in everyday activity. Cognitive Development, 7, 213-233. doi:10.1016/0885-2014(92)90012-G

Carlson, S. M., Davis, A. C., \& Leach, J. G. (2005). Less is more: Executive function and symbolic representation in preschool children. Psychological Science, 16, 609-616. doi:10.1111/j.1467-9280.2005 .01583.x

Ceci, S. J., \& Bruck, M. (1993). The suggestibility of the child witness: A historical review and synthesis. Psychological Bulletin, 113, 403-439. doi:10.1037/0033-2909.113.3.403

Ceci, S. J., \& Bruck, M. (2006). Children's suggestibility: Characteristics and mechanisms. In R. V. Kail (Ed.), Advances in child development and behavior (pp. 247-281). San Diego, CA: Elsevier. doi:10.1016/S00652407(06)80009-1

Chouinard, M. M. (2007). Children's questions: A mechanism for cognitive development. Monographs of the Society for Research in Child Development, 72, 1-112. doi:10.1111/j.1540-5834.2007.00412.x

Dunn, J. (2004). Children's friendships: The beginnings of intimacy. Malden, MA: Blackwell.

Einav, S., \& Robinson, E. J. (2010). Children's sensitivity to error magnitude when evaluating informants. Cognitive Development, 25, 218 232. doi:10.1016/j.cogdev.2010.04.002

Field, D. (1987). A review of preschool conservation training: An analysis of analyses. Developmental Review, 7, 210-251. doi:10.1016/02732297(87)90013-X

Fitneva, S. A. (2010). Children's representation of child and adult knowledge. Journal of Cognition and Development, 11, 458-484. doi: $10.1080 / 15248371003700023$

Fitneva, S. A. (2012). Beyond answers: Questions and children's learning. In J. P. de Ruiter (Ed.), Questions: Formal, functional, and interactional perspectives (pp. 165-178). Cambridge, England: Cambridge University Press.

Fitneva, S. A., \& Dunfield, K. A. (2010). Selective information seeking after a single encounter. Developmental Psychology, 46, 1380-1384. doi: $10.1037 / \mathrm{a} 0019818$

Frazier, B. N., Gelman, S. A., \& Wellman, H. M. (2009). Preschoolers' search for explanatory information within adult-child conversation. Child Development, 80, 1592-1611. doi:10.1111/j.1467-8624.2009 .01356.x

Gelman, S. A. (2009). Learning from others: Children's construction of concepts. Annual Review of Psychology, 60, 115-140. doi:10.1146/ annurev.psych.59.103006.093659

Gelman, S. A., \& Bloom, P. (2007). Developmental changes in the understanding of generics. Cognition, 105, 166-183. doi:10.1016/j.cognition 2006.09.009

Harris, P. L. (2002a). Checking our sources: The origins of trust in testimony. Studies in History and Philosophy of Science Part A, 33, 315-333. doi:10.1016/S0039-3681(02)00007-9

Harris, P. L. (2002b). What do children learn from testimony? In P. Carruthers, S. Stich, \& M. Siegal (Eds.), The cognitive basis of science (pp. 316-334). New York, NY: Cambridge University Press. doi: $10.1017 / \mathrm{CBO} 9780511613517.018$

Harris, P. L., \& Koenig, M. (2006). Trust in testimony: How children learn about science and religion. Child Development, 77, 505-524. doi: 10.1111/j.1467-8624.2006.00886.x

Harris, P. L., Pasquini, E. S., Duke, S., Asscher, J. J., \& Pons, F. (2006). Germs and angels: The role of testimony in young children's ontology. Developmental Science, 9, 76-96. doi:10.1111/j.1467-7687.2005 .00465.x 
Hartup, W. W., \& Stevens, N. (1997). Friendships and adaptation in the life course. Psychological Bulletin, 121, 355-370. doi:10.1037/0033-2909 .121.3.355

Heyman, G. D., \& Legare, C. H. (2005). Children's evaluation of sources of information about traits. Developmental Psychology, 41, 636-647. doi:10.1037/0012-1649.41.4.636

Howes, C. (2009). Friendship in early childhood. In K. H. Rubin, W. M. Bukowski, B. Laursen (Eds.), Handbook of peer interactions, relationships, and groups (pp. 180-194). New York, NY: Guilford Press.

Hughes, C., \& Dunn, J. (1998). Understanding mind and emotion: Longitudinal associations with mental-state talk between young friends. Developmental Psychology, 34, 1026-1037. doi:10.1037/0012-1649.34.5 .1026

Jaswal, V. K. (2004). Don't believe everything you hear: Preschoolers' sensitivity to speaker intent in category induction. Child Development, 75, 1871-1885. doi:10.1111/j.1467-8624.2004.00822.x

Jaswal, V. K. (2010). Believing what you're told: Young children's trust in unexpected testimony about the physical world. Cognitive Psychology, 61, 248-272. doi:10.1016/j.cogpsych.2010.06.002

Jaswal, V. K., Carrington Croft, A., Setia, A. R., \& Cole, C. A. (2010). Young children have a specific, highly robust bias to trust testimony. Psychological Science, 21, 1541-1547. doi:10.1177/0956797610383438

Jaswal, V. K., \& Neely, L. A. (2006). Adults don't always know best: Preschoolers use past reliability over age when learning new words. Psychological Science, 17, 757-758. doi:10.1111/j.1467-9280.2006 .01778.x

Koenig, M. A., \& Harris, P. L. (2005). Preschoolers mistrust ignorant and inaccurate speakers. Child Development, 76, 1261-1277. doi:10.1111/j .1467-8624.2005.00849.x

Koenig, M. A., \& Jaswal, V. K. (2011). Characterizing children's expectations about expertise and incompetence: Halo or pitchfork effects? Child Development, 82, 1634-1647. doi:10.1111/j.1467-8624.2011 .01618.x

Lutz, D. J., \& Keil, F. C. (2002). Early understanding of the division of cognitive labor. Child Development, 73, 1073-1084. doi:10.1111/14678624.00458

Mascaro, O., \& Sperber, D. (2009). The moral, epistemic, and mindreading components of children's vigilance towards deception. Cognition, 112, 367-380. doi:10.1016/j.cognition.2009.05.012

Melnyk, L., Crossman, A. M., \& Scullin, M. H. (2007). The suggestibility of children's memory. In M. P. Toglia, J. D. Read, D. F. Ross, \& R. C. L. Lindsay (Eds.), The handbook of eyewitness psychology. Vol. I: Memory for events (pp. 401-427). Mahwah, NJ: Erlbaum.

Mills, C. M., Legare, C. H., Bills, M., \& Mejias, C. (2010). Preschoolers use questions as a tool to acquire knowledge from different sources. Journal of Cognition and Development, 11, 533-560. doi:10.1080/ 15248372.2010 .516419

Newcomb, A. F., \& Bagwell, C. L. (1995). Children's friendship relations: A meta-analytic review. Psychological Bulletin, 117, 306-347. doi: 10.1037/0033-2909.117.2.306

Nurmsoo, E., \& Robinson, E. J. (2009a). Children's trust in previously inaccurate informants who were well or poorly informed: When past errors can be excused. Child Development, 80, 23-27. doi:10.1111/j .1467-8624.2008.01243.x

Nurmsoo, E., \& Robinson, E. J. (2009b). Identifying unreliable informants: Do children excuse past inaccuracy? Developmental Science, 12, 41-47. doi:10.1111/j.1467-7687.2008.00750.x

O'Neill, D. K., Astington, J. W., \& Flavell, J. H. (1992). Young children's understanding of the role that sensory experiences play in knowledge acquisition. Child Development, 63, 474-490. doi:10.2307/1131493

O’Neill, D. K., \& Chong, S. C. F. (2001). Preschool children's difficulty understanding the types of information obtained through the five senses. Child Development, 72, 803-815. doi:10.1111/1467-8624.00316
Perner, J., \& Ruffman, T. (1995). Episodic memory and autonoetic consciousness: Developmental evidence and a theory of childhood amnesia. Journal of Experimental Child Psychology, 59, 516-548. doi:10.1006/ jecp.1995.1024

Piaget, J. (1929). The child's conception of the world. New York, NY: Harcourt Brace.

Pillow, B. H. (1989). Early understanding of perception as a source of knowledge. Journal of Experimental Child Psychology, 47, 116-129. doi:10.1016/0022-0965(89)90066-0

Pirolli, P., \& Card, S. (1999). Information foraging. Psychological Review, 106, 643-675. doi:10.1037/0033-295X.106.4.643

Poole, D. A., \& Lindsay, D. S. (2001). Children's eyewitness reports after exposure to misinformation from parents. Journal of Experimental Psychology: Applied, 7, 27-50. doi:10.1037/1076-898X.7.1.27

Robinson, E. J., Butterfill, S. A., \& Nurmsoo, E. (2011). Gaining knowledge via other minds: Children's flexible trust in others as sources of information. British Journal of Developmental Psychology, 29, 961980. doi:10.1111/j.2044-835X.2011.02036.x

Robinson, E. J., Champion, H., \& Mitchell, P. (1999). Children's ability to infer utterance veracity from speaker informedness. Developmental Psychology, 35, 535-546. doi:10.1037/0012-1649.35.2.535

Robinson, E. J., Haigh, S. N., \& Nurmsoo, E. (2008). Children's working understanding of knowledge sources: Confidence in knowledge gained from testimony. Cognitive Development, 23, 105-118. doi:10.1016/j .cogdev.2007.05.001

Robinson, E. J., Haigh, S. N., \& Pendle, J. E. C. (2008). Children's working understanding of the knowledge gained from seeing and feeling. Developmental Science, 11, 299-305. doi:10.1111/j.1467-7687 .2008.00676.x

Robinson, E. J., \& Whitcombe, E. L. (2003). Children's suggestibility in relation to their understanding about sources of knowledge. Child Development, 74, 48-62. doi:10.1111/1467-8624.t01-1-00520

Shatz, M. (1979). How to do things by asking: Form-function pairings in mothers' questions and their relation to children's responses. Child Development, 50, 1093-1099. doi:10.2307/1129336

Simon, H. A. (1971). Designing organizations for an information-rich world. In M. Greenberger (Ed.), Computers, communications, and the public interest (pp. 37-72). Baltimore, MD: Johns Hopkins Press.

Sinclair, A., \& Van Gessel, R. (1990). The form and function of questions in children's conversations. Journal of Pragmatics, 14, 923-944. doi: 10.1016/0378-2166(90)90047-H

Sperber, D., Clément, F., Heintz, C., Mascaro, O., Mercier, H., Origgi, G., \& Wilson, D. (2010). Epistemic vigilance. Mind \& Language, 25, 359-393. doi:10.1111/j.1468 0017.2010.01394.x

Taylor, M., Esbensen, B. M., \& Bennett, R. T. (1994). Children's understanding of knowledge acquisition: The tendency for children to report that they have always known what they have just learned. Child Development, 65, 1581-1604. doi:10.2307/1131282

Tizard, B., \& Hughes, M. (1984). Young children learning. Cambridge, MA: Harvard University Press. doi:10.1002/9780470774328

Vygotsky, L. S. (1929). The problem of the cultural development of the child. Journal of Genetic Psychology, 36, 415-434. doi:10.1080/ 08856559.1929 .10532201

Zelazo, P. D., Müller, U., Frye, D., \& Marcovitch, S. (2003). The development of executive function in early childhood. Monographs of the Society for Research in Child Development, 68, 1-136. doi:10.1111/j .1540-5834.2003.06803001.x

Received June 16, 2011

Revision received July 31, 2012 Accepted October 8, 2012 